\title{
Efeito do chá verde (Camelia sinensis) em ratos com obesidade induzida por dieta hipercalórica
}

\author{
Antiobesity effects of green tea (Camelia sinensis) in high caloric diet-induced obese rats
}

Marta Vera-Cruz'; Elaine Nunes²; Lívia Mendonça3 ; Érika Chaves; Maria Luiza de Lima Aguilar Fernandes ${ }^{5}$

Unitermos
Obesidade
Chá verde
Sinalização da insulina
Receptor da insulina
Shc
Imuno-histoquímica

\section{resumo}

Introdução: A obesidade é fator de risco para várias doenças. Estudos têm demonstrado que os polifenóis do chá verde auxiliam na perda de peso e interferem nos mecanismos de diversas doenças. A insulina, agindo por meio de seu receptor (IR), desencadeia uma série de respostas. A via IR/Shc é ligada ao crescimento celular e à mitogênese. Objetivos: Estudar o efeito do chá verde no peso corporal e no teste de tolerância à glicose (GTT). No fígado, estudar a fosforilação do IR, a presença e a expressão de IR e Shc e suas alterações morfológicas. Material e métodos: Ratos Wistar, jovens e tratados com dieta hipercalórica ou dieta própria para ratos, foram submetidos a tratamento com chá verde. Para retirada do fígado, após anestesia, foi infundida insulina ou solução salina. Para avaliar o grau de fosforilação do IR, o fragmento foi homogeneizado e submetido a técnicas de imunoprecipitação e imunoblotting. Para análise morfológica, foi utilizada a técnica de coloração por hematoxilina e eosina e para localizar a presença de IR e Shc, técnica de imuno-histoquímica. Resultados e conclusão: Observamos diminuição do peso corporal e da esteatose no fígado e melhora no GTT. Houve aumento da fosforilação do IR no fígado dos animais obesos tratados com relação aos obesos não submetidos a tratamento. Verificaram-se lesões que poderiam ser associadas ao tratamento, como necrose focal. A análise imuno-histoquímica demonstrou presença de IR e Shc em todos os grupos estudados e sugeriu alterações na expressão de IR e Shc nos grupos obesos e obesos tratados.

\section{abstract}

Introduction: Obesity is a risk factor for several diseases. Studies have shown that polyphenols in green tea aid in weight loss and influence the mechanisms of several diseases. Insulin, acting through its receptor (IR), triggers a series of responses. IR/Shc pathway is linked to cell growth and mitogenesis. Objectives: To investigate the effect of green tea on body weight and on glucose tolerance test (GTT). To study IR phosphorylation, IR/Shc presence and expression and their morphological changes in the liver. Material and methods: Young Wistar rats were fed with high-calorie diet or proper rat food diet and subsequently were treated with green tea. After anesthesia, insulin or saline solution was infused to remove the liver. A liver fragment was homogenized and underwent immunoprecipitation and immunoblotting in order to assess IR phosphorylation levels. Hematoxylin and eosin staining was applied for morphological analysis and immunohistochemistry was carried out to locate the presence of IR and Shc. Results and conclusion: It was observed a reduction in body weight and in liver steatosis as well as an improvement in GTT. There was also an increase in IR phosphorylation in treated animals in comparison with non-treated ones. Lesions such as focal necrosis were observed and may be associated with the treatment. The immunohistochemical analysis demonstrated the presence of IR and Shc in all groups and suggested changes in IR and Shc expression in both treated and non-treated groups.

\section{key words}

Obesity

Green tea

Insulin signaling

Insulin receptor

Shc

Immunohystochemistry

1. Mestra em Ciências Médicas pela Universidade do Estado do Rio de Janeiro (UER)).

2. Graduada em Nutrição pela UER].

3. Graduanda em Nutrição pela UER).

4. Mestra em Ciências Morfológicas pela UER); professora de Anatomia Patológica da Universidade Gama Filho (UCF) e de Patologia da Universidade Estácio de Sá (UNESA).

5. Doutora em Clínica Médica pela Universidade de Campinas (UNICAMP); professora adjunta da disciplina de Patologia Geral da Faculdade de Ciências Médicas (FCM) da UER). 


\section{Introdução}

A obesidade é considerada atualmente um problema de saúde pública e está relacionada com várias doenças, como diabetes mellitus tipo 2 (DM2), síndrome metabólica (SM), esteatose hepática, cânceres, entre outras(2).

O chá verde tem sido muito utilizado pela divulgação de seus efeitos, pelo baixo custo e pela fácil acessibilidade. Em nosso meio, tem sido utilizado principalmente por pessoas obesas, com sobrepeso e magras com a finalidade de emagrecimento ou manutenção do peso.

O chá verde e seus componentes têm demonstrado significantes propriedades antidiabéticas, antioxidantes, anticarcinogênicas, entre outras, em estudos em humanos, animais e in vitro. Seus principais componentes químicos terapêuticos são as catequinas, sendo a galato-3-epigalocatequina (ECCG) a mais abundante e importante do ponto de vista farmacológico ${ }^{(2,8)}$.

Sabemos que a obesidade desencadeia processos de resistência à insulina. A insulina, além de atuar na homeostasia da glicose, regula a síntese e o estoque da gordura e a síntese proteica, agindo também em processos não metabólicos, como o crescimento e a diferenciação celular.

De forma simplificada, podemos dizer que a insulina, ao se ligar a seu receptor específico, o receptor de insulina (IR), faz com que este sofra autofosforilação em tirosina, tornando-se capaz de fosforilar e acionar duas importantes vias: a metabólica, por meio dos substratos do receptor da insulina (IRSs), e a de crescimento ou proliferativa, pela fosforilação da proteína semelhante ao colágeno com homologia Src(Shc), permitindo que as diversas ações da insulina possam ser exercidas ${ }^{(1)}$. A proteína Shc também tem sido descrita na carcinogênese e em outros processos que envolvem espécies reativas de oxigênio ${ }^{(3)}$.

O fígado exerce papel central no metabolismo de glicose e lipídios, e a resistência à insulina no fígado é grandemente responsável pelo desenvolvimento da hiperglicemia do jejum e da doença gordurosa não alcoólica do fígado (DGNAF), alterações muito comuns na obesidade.

Efeitos adversos pelo uso do chá verde e seus componentes, como a hepatotoxicidade, têm sido relatados em seres humanos ${ }^{(5)}$.

No sentido de contribuir para o entendimento das ações e dos mecanismos moleculares do chá verde, é importante estudar seus efeitos no peso corporal e no teste de tolerância à glicose; no fígado, suas alterações morfológicas, a fosforilação do IR e a expressão do IR e da Shc.

\section{Material e métodos}

Ratos da linhagem Wistar-Hannover, machos, após desmame, fornecidos pelo Laboratório de Cirurgia Experimental da Universidade do Estado do Rio de Janeiro (UERJ), foram divididos de forma aleatória em dois grupos de acordo com a dieta a que foram submetidos. O denominado grupo obeso foi constituído por animais que receberam dieta com alta densidade energética (ADE) para induzir obesidade e o denominado grupo controle, por animais que receberam dieta própria para ratos (Purina). Os experimentos seguiram as normas estabelecidas no Colégio Brasileiro de Experimentação Animal e aprovadas pelo Comitê de Ética Animal do Centro Biomédico da UERJ.

Após seis meses, caracterizou-se o processo de obesidade e todos os animais foram subdivididos aleatoriamente em grupos tratados e não tratados. Os grupos submetidos a tratamento receberam $2 \mathrm{ml}$ de chá preparado com $1 \mathrm{~g}$ de folhas de chá verde seco (Midori Ltda.) em $75 \mathrm{ml}$ de água deionizada, fervida a $90^{\circ} \mathrm{C}$ durante as duas semanas finais do experimento, por gavagem, para garantir a total ingestão do chá.

Todos os grupos receberam água ad libitum durante todo o período do estudo.

\section{Teste de tolerância à glicose (GTT)}

No dia do experimento, os animais foram submetidos a jejum de seis a oito horas, anestesiados com tiopental sódico e utilizados após perda de reflexo corneano ou pedioso. A solução de glicose utilizada foi de $25 \%$ (calcula-se oito vezes o peso do animal para dose ideal). Após a infusão da glicose, as glicemias foram mensuradas nos tempos de 0, 15, 30, 60 e 120 minutos.

\section{Extração do fígado: imunoprecipitação e immunoblotting}

Para retirada do fígado, os animais foram submetidos a jejum e anestesiados da maneira já descrita. Foi realizada laparotomia mediana e injetada em bolo, na veia porta, solução salina (grupo negativo) ou $500 \mu \mathrm{g} / \mathrm{kg}$ de insulina regular, diluída em $120 \mu \mathrm{g} / \mathrm{ml}$ em igual volume de salina (grupo positivo). Após 60 segundos, tempo de melhor ação da insulina no fígado (7), fragmentos do órgão foram retirados e imediatamente homogeneizados em tampão específico para os procedimentos de imunoprecipitação. O material insolúvel foi removido por centrifugação a $4^{\circ} \mathrm{C}$. A concentração de proteína do sobrenadante foi 
determinada e todas as amostras contendo igual quantidade de proteína total foram incubadas com $10 \mu \mathrm{l}$ de anti-IR a $4^{\circ} \mathrm{C}$, sendo realizada a seguir incubação com proteína A-Sepharose $6 \mathrm{MB}$. Os pellets foram lavados com tampão a $4^{\circ} \mathrm{C}$ e ressuspensos em tampão de Laemmli, fervidos e, em seguida, carregados no gel de poliacrilamida. Após o término da separação, as proteínas foram transferidas para uma membrana de nitrocelulose (GE cat. 806204-26), "blotadas" com anticorpos antifosfotirosina e, então, reveladas por quimiluminescência.

\section{Apresentação dos dados e análise estatística}

As bandas específicas presentes nos blots foram quantificadas por densitometria. Os dados foram analisados por teste $t$ de Student para dados não pareados com significância de $5 \%(p<0,05)$ e resultados expressos com a média +/- erro padrão de uma variação percentual entre os grupos analisados. Para análise dos efeitos dos testes de tolerância à glicose e peso corporal utilizou-se a análise de variância (ANOVA) para dados multivariáveis com significância de $5 \%(p<0,05)$.

\section{Processamento histológico e imuno- histoquímico}

Fragmentos de fígado fixados em formol neutro incluídos em parafina foram cortados e corados com hematoxilina-eosina para microscopia ótica e incubados com anticorpos anti-IR e anti-Shc (Santa Cruz, EUA) para análise imuno-histoquímica. A recuperação antigênica foi feita em tampão citrato $(\mathrm{pH} 6)$ em panela a vapor (Clocking Chamber Pro-Biocare Medica). O controle negativo constituiu da omissão do anticorpo primário. No controle positivo foi utilizado tecido pancreático para observação das ilhotas de Langerhans.

O exame e a documentação do material foram feitos em microscópio Leitz Dialux. A severidade das alterações hepáticas, tais como necrose e esteatose, observada pela microscopia ótica, foi graduada nos termos da seguinte escala arbitrária: nihil (ausência de alterações do tipo esteatose e ou necrose celular), + ou leve (no caso de presença esparsa de esteatose e/ou necrose), ++ ou moderada (quando as lesões descritas mostram tendência à confluência) e +++ ou acentuada (quando as lesões são difusas).

Para a leitura das lâminas, foi considerado padrão de normalidade para o fígado: bom estado de conservação, ausência de infiltrado inflamatório, homogeneidade de aspecto, identificação dos lóbulos hepáticos e espaço porta íntegro, veias hepáticas bem definidas, cordões sinusoidais presentes e íntegros. Os hepatócitos considerados dentro dos limites da normalidade foram aqueles com um núcleo central e nucléolo evidente, citoplasma com áreas basófilas e acidófilas e ausência de vacuolização.

As células hepáticas foram incubadas com anti-IR e antiShc e avaliadas de acordo com escala arbitrária e objetiva de 40. Foi considerada marcação citoplasmática, sendo excluídos aqueles com outro tipo de reatividade: nihil (ausência de positividade), + ou leve (células esparsas), ++ ou moderada (acima de uma por campo) e +++ ou positividade acentuada (quando confluente).

\section{Resultados}

\section{Efeito da dieta de alta densidade energética (ADE)}

Inicialmente, submeteu-se um grupo de 16 animais no primeiro dia de desmame à $\mathrm{ADE}$ durante seis meses. Todos os animais submetidos à $\mathrm{ADE}$ apresentaram ganho corporal significativamente superior ao grupo submetido à dieta padrão $p<0,01$ (Figura 1).

\section{Efeito do chá verde no peso corporal}

Foi observada diferença significativa de perda de peso corporal nos animais controles tratados com chá verde em relação ao grupo de animais controles que não receberam o mesmo tratamento $p<0,01$ (Figura 2).

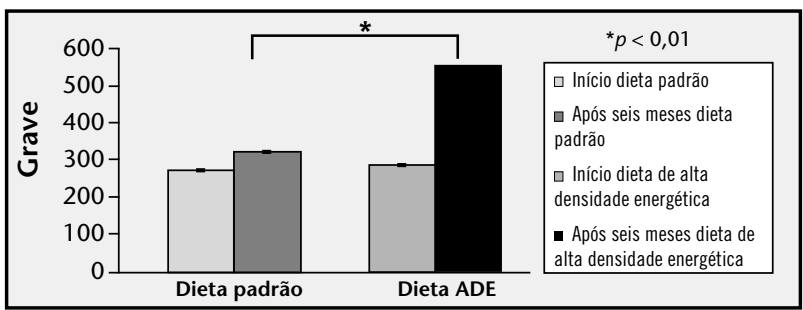

Figura 1 - Efeito da ADE no peso corporal $A D E$ : dieta de alta densidade energética.

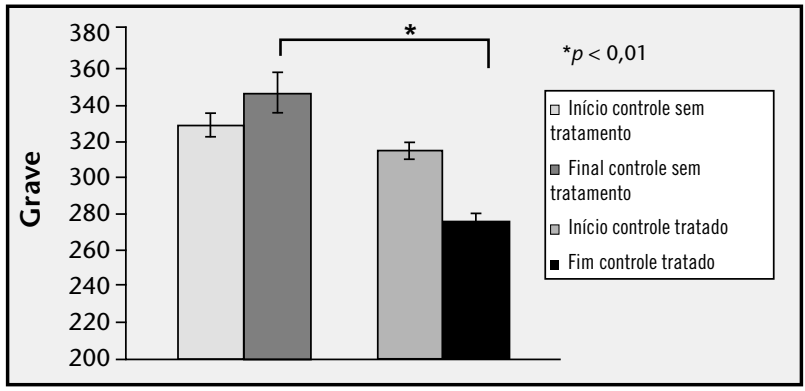

Figura 2 - Efeito do tratamento com chá verde no peso corporal de animais controles 
Também foi notada diferença significativa de perda de peso corporal nos animais obesos tratados com chá verde em relação ao grupo de animais obesos que não receberam o mesmo tratamento $p<0,01$ (Figura 3).

\section{Efeito do chá verde no GTT}

Ao analisarmos as glicemias após infusão da glicose nos tempos determinados, observamos que os animais obesos tratados apresentaram diminuição significativa da glicemia em relação aos grupos controles e obesos sem tratamento nos tempos de 60 e 120 minutos $p<0,001$. Os animais do grupo controle submetidos a tratamento apresentaram glicemias significativamente inferiores no tempo de 120 minutos em relação aos controles e aos obesos sem tratamento $p<0,05$. $O$ grupo de animais obesos sem tratamento manteve glicemias significativamente mais elevadas em relação a todos os grupos $p<0,001$ (Figura 4).

\section{Efeito do chá verde na expressão e na fosforilação em tirosina do IR no fígado}

Foram realizados três experimentos utilizando técnicas de imunoprecitação e immunoblotting em extratos de fígado. Cada experimento utilizou um animal de cada um dos quatro grupos propostos, em um total de 12 animais. Não

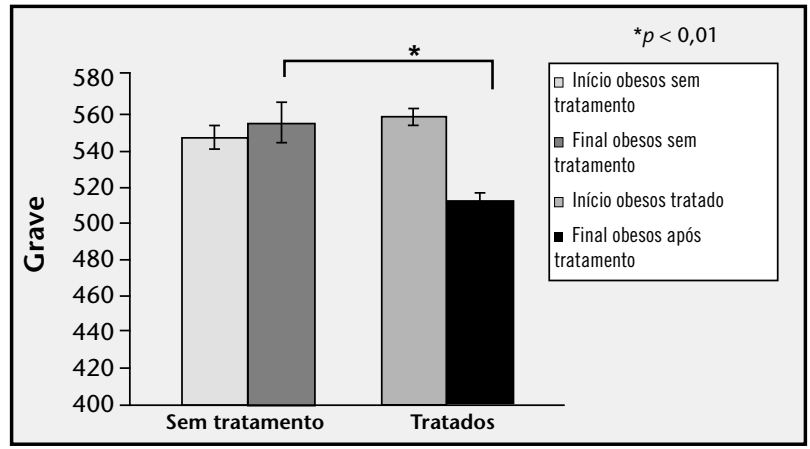

Figura 3 - Efeito do tratamento com chá verde no peso corporal dos animais obesos

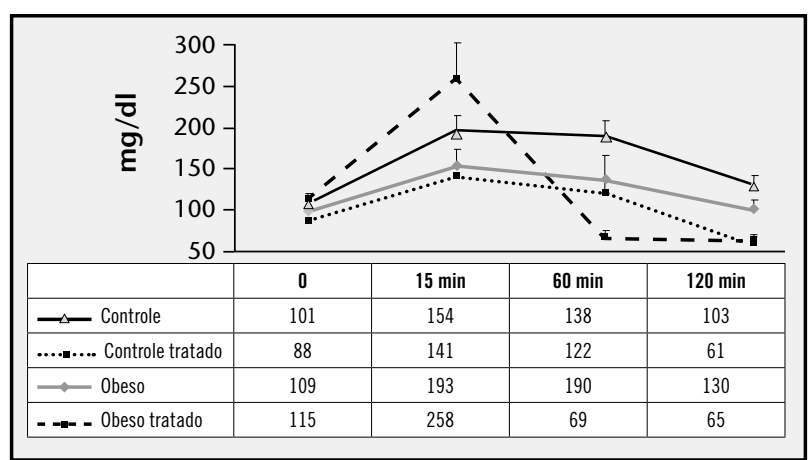

Figura 4 - GTT. As glicemias do sangue venoso foram aferidas nos tempos determinados e analisadas estatisticamente por ANOVA de comparações múltiplas GTT: teste de tolerância à glicose; ANOVA: análise de variância. foi detectada alteração significativa no nível de expressão proteica do receptor de insulina em todos os grupos estudados, como determinado após stripping das membranas de nitrocelulose dos imunoprecipitados de anti-IR e posterior immunoblotting com anticorpo anti-IR.

Houve aumento significativo no grau de fosforilação em tirosina do IR no fígado dos animais obesos tratados com chá verde em relação ao grupo de animais obesos não submetido ao tratamento $p<0,05$ (Figura 5).

\section{Análise morfológica}

- Animais controles: dentro dos limites da normalidade (Figura 6A);

- controles tratados: hiperplasia e hipertrofia de células de Kupffer com pigmentos de hemossiderina. Microvacúolos citoplasmáticos, congestão sinusoidal, discreta irregularidade estrutural de localização centrolobular, dilatação sinusoidal, vacuolização centrolobular, necrose hepatocitária focal (++) (Figura 6B);

- animais obesos: esteatose macro e microvesicular (++ e +++) periportal e centrolobular, edema, vacuolização citoplasmática e nuclear, infiltrado inflamatório (+), hipertrofia e hiperplasia das células de Kupffer, balonização de hepatócitos (Figura 6C);

- animais obesos tratados: esteatose centrolobular micro e macrovesicular ( $+\mathrm{e}++)$, em menor escala quando comparados com os animais obesos que não tomaram chá. Vacuolização citoplasmática, degeneração tipo glicogênica, balonização de hepatócitos, hiperplasia e hipertrofia das células de Kupffer, pigmentos de hemossiderina, congestão e

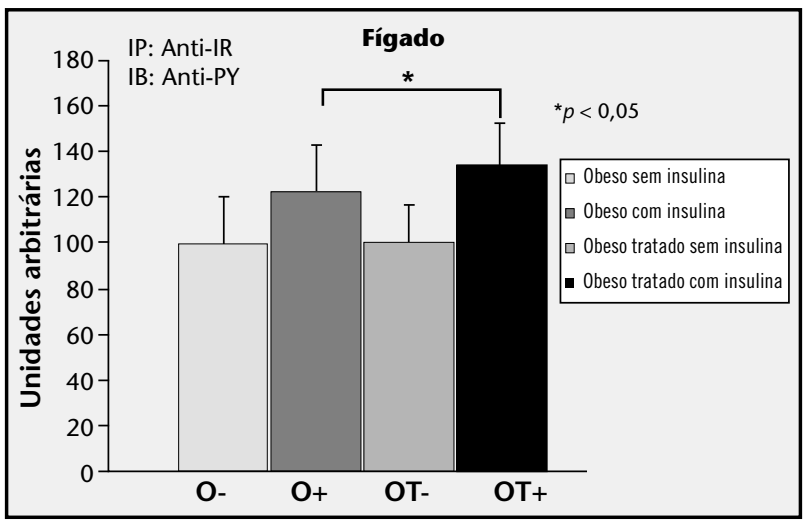

Figura 5 - Efeito do tratamento com chá verde no grau de fosforilação do IR em fígado de ratos obesos IR: receptor de insulina. 
dilatação sinusoidal centrolobular, destrabeculação, infiltrado inflamatório discreto, por vezes moderado, em uma ocasião, infiltrado portal e necrose hepatocelular focal $(++\mathrm{a}+++)$. Esse conjunto de lesões caracteriza uma hepatite reacional por provável toxicidade (Figura 6D).

\section{Receptor da insulina}

- Controles: positividade acentuada nos animais controles em relação aos outros grupos incubados com o IR (+++) (Figura 7A);

- controles tratados: positividade moderada, padrão citoplasmático (++) (Figura 7B);

- obesos: positividade leve (+). Níveis bem inferiores aos encontrados nos ratos controles e controles tratados com chá verde (Figura $\mathbf{7 C}$ );

- obesos tratados: positividade citoplasmática moderada em grupos de células, maior vacuolização intracitoplasmática (++) (Figura 7D).

\section{Proteína Shc}

- Controles: positividade leve, centrolobular (+) (Figura 8A);

- controles tratados: positividade leve, sem grandes variações, padrão citoplasmático (+) (Figura 8B);

- obesos: observou-se marcação ou positividade em nível considerado acentuado, principalmente nas células com depósitos de gordura (esteatose) e de infiltrado inflamatório. A expressão foi mais elevada

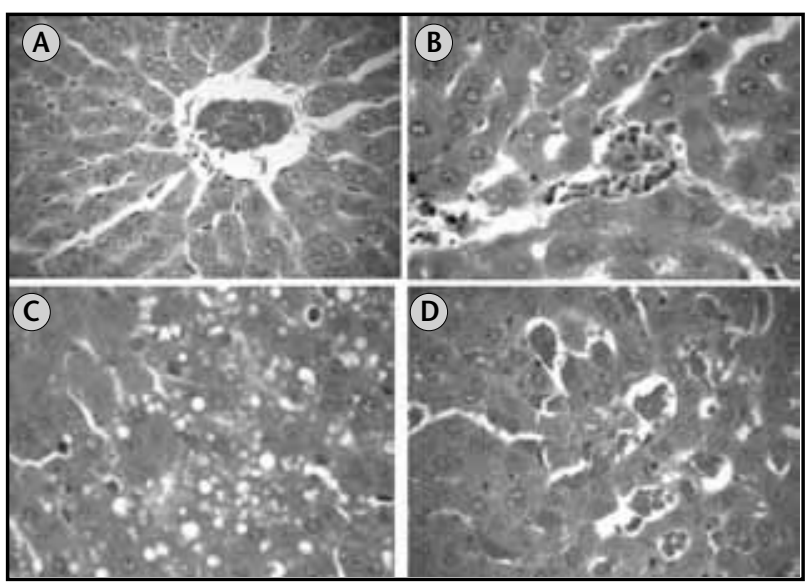

Figura 6 - Achados histopatológicos do fígado de ratos Wistar. (A) Controle: hepatócitos normais em relação à microscopia ótica (HE, 20x [7.1]); (B) controle tratado: destrabeculação, necrose hepatocitária focal (HE, 40x [7.1]), (C) obeso: esteatose macro e microvacuolar (HE, 40x [5.1]); (D) obeso tratado: congestão acentuada, dilatação sinusoidal (HE, 40x [4.1])

$H E$ : hematoxilina e eosina. em relação aos modelos controles e controles tratados (+++) (Figura 8C);

- obesos tratados: positividade citoplasmática fezse moderada, em certos grupos de células, maior vacuolização e maior concentração do anticorpo (++) (Figura 8D).

\section{Discussão}

Neste trabalho avaliamos os efeitos do chá verde no peso corporal e no GTT. No fígado, estudamos as alterações morfológicas, a fosforilação do IR e a expressão do IR e da Shc por análise imuno-histoquímica.

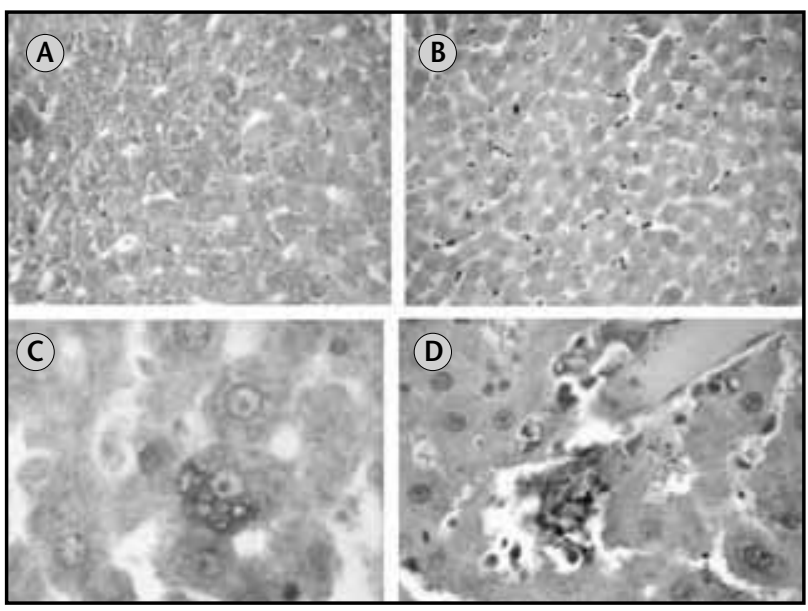

Figura 7 - Positividade da reação anti-IR em fígado de ratos Wistar. (A) Controle: acentuada positividade (anti-IR, 20x [5.1]); (B) controle tratado: moderada positividade, hipertrofia e hiperplasia de células de Kupffer (anti-IR, 20x [4.1]); (C) obeso: leve positividade em citoplasma (anti-IR, 40x [4.1]); (D) obeso tratado: positividade leve, necrose focal (anti-IR, $40 \times[5.1])$

IR: receptor de insulina.
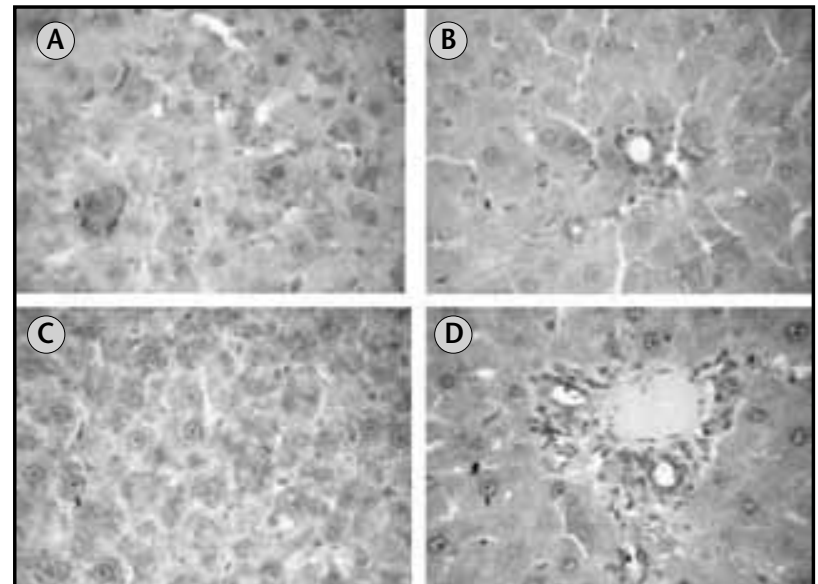

Figura 8 - Positividade da reação anti-Shc em fígado de ratos Wistar. (A) controle: positividade moderada (anti-Shc, 40x aproximadamente 5.1); (B) controle tratado: positividade leve, necrose hepatocitária focal (anti-Shc, 40x aproximadamente 5.1); (C) obeso: acentuada positividade (anti-Shc, 40x aproximadamente 5.1); (D) obeso tratado: positividade acentuada, discreto infiltrado portal (anti-Shc, 40x aproximadamente 7.1) Shc: proteína semelhante ao colágeno com homologia Src. 
Nossos resultados evidenciaram uma perda do peso corporal significativa nos animais obesos e controles tratados com chá verde.

No GTT, encontramos uma diminuição significativa da glicemia nos tempos de 60 e 120 minutos nos grupos tratados com chá verde e glicemias significativamente e persistentemente mais elevadas no grupo obeso sem tratamento.

Chamou atenção à microscopia uma diversidade de lesões hepáticas em todos os grupos analisados, exceto dos animais controles não submetidos a tratamento, que apresentaram fígado sem alterações.

Nos animais obesos observou-se esteatose macro e micro vesicular associadas a um processo inflamatório leve. Foi verificada uma diminuição dessas alterações nos animais obesos tratados, o que confirmou a diminuição da gordura, já que esses modelos perderam peso corporal.

A variabilidade genética é um fator crítico que influencia a susceptibilidade da lesão induzida por droga. Tal lesão ocorre em três possibilidades: a) toxicidade direta hepatocitária ou em células epiteliais biliares, levando a necrose, apoptose ou perda da função celular; b) pela conversão de uma toxina xenobiótica para uma toxina ativa; c) por mecanismos imunes, usualmente por droga ou metabólito agindo como um hapteno, convertendo a proteína celular em um imunógeno. O significado da esteatose depende da causa e da gravidade.

Os animais que receberam tratamento com chá verde apresentaram lesões no fígado, o que nos surpreendeu, já que o uso do chá ocasionou melhoria no sinal insulínico e diminuição da gordura corporal. Essas lesões se caracterizaram por congestão, infiltrado inflamatório focal, hipertrofia e hiperplasia de células de Kupffer com pigmentos de hemossiderina. As lesões descritas podem estar relacionadas com um processo de citotoxicidade ocasionado pelo chá verde, como acima mencionado, provavelmente sendo o resultado de uma agressão multifatorial. Os pigmentos de hemossiderina estão relacionados com o ferro presente nas hemácias, caracterizando a digestão pelos macrófagos no processo de depuração sinusoidal proveniente da congestão. A necrose hepatocelular focal também foi encontrada nos animais que tomaram o chá.

Distinções entre apoptose, necrose e autofagia implicam em diferenças no modo de morte e em alterações morfológicas, bioquímicas e moleculares. A morte celular programada é um conceito importante e é geneticamente controlada. A apoptose e a autofagia são os dois tipos fundamentais de morte celular programada. Além disso, achados recentes evidenciam que a necrose, em certos casos, pode ser iniciada ou modulada pelos mecanismos de controle programado(4).

Os camundongos alimentados com dieta de ADE e tratados com a EGCG apresentaram uma diminuição da esteatose hepática e dos níveis séricos de amino alanina transferase. $\mathrm{O}$ estudo demonstrou também uma diminuição da resistência à insulina quando a esteatose foi suprimida ${ }^{(2)}$.

Com relação à fosforilação do IR, encontramos um aumento no grau de fosforilação em tirosina do IR no fígado de ratos obesos tratados com chá verde comparado ao grupo de animais obesos não submetidos ao tratamento. Sabemos da importância do fígado na sinalização da insulina e esses efeitos no grau de fosforilação podem ter implicações na melhora da resistência à insulina.

Estudos em camundongos knockout para o IR no fígado (LIRKO) demonstraram um aumento da glicemia e acentuada hiperinsulinemia nesses animais. Esses achados podem ser explicados pelo impedimento da captação e degradação da insulina pelo fígado, que é mediada pelo seu receptor. A análise histológica do fígado desses animais revelou ainda um aumento do acúmulo de lipídios acompanhado de uma diminuição de $50 \%$ nos níveis de albumina sérica, sugerindo um decréscimo na função hepática ${ }^{(1)}$.

$\mathrm{Na}$ análise imuno-histoquímica dos fígados incubados com anti-IR, houve positividade em todos os modelos estudados, caracterizando a presença do receptor de insulina. Os animais controle e controle tratado sinalizaram uma variação do anti-IR muito discreta entre si, na qual o controle apresentou uma distribuição levemente maior do IR com relação ao controle tratado. Nos animais obesos tratados comparados aos obesos sem tratamento, foi sinalizado um leve aumento do mesmo em sua distribuição.

Nosso trabalho também analisou a proteína Shc A no que diz respeito à presença e à expressão nos modelos aqui propostos.

A proteína Shc A é expressa em três isoformas com massas moleculares distintas: 46,52 e $66 \mathrm{Kd}$. A isoforma p66Shc faria parte de um complexo sistema regulador endógeno mitocondrial na produção de radicais livres, bem como de apoptose programada ${ }^{(3,6)}$.

De acordo com a análise imuno-histoquímica, a presença da proteína Shc foi detectada em todos os modelos estudados, sugerindo uma expressão maior nos animais obesos, com distribuição acentuada difusa e intracitoplasmática e, nos obesos tratados com uma distribuição 
também difusa e citoplasmática, em menor intensidade. Os animais controles e controles tratados apresentaram distribuição muito discreta da proteína.

Observamos também na imuno-histoquímica uma exacerbada reatividade da Shc A nos animais tratados que apresentavam lesões do tipo necrose, esteatose, congestão, hipertrofia e hiperplasia Kupfferiana, com distribuição acentuada nos animais obesos e moderada nos obesos tratados, como relatado anteriormente.

A necrose foi um dos achados histopatológicos nos animais tratados com chá verde. A p66Shc parece induzir à apoptose ${ }^{(6)}$. Essas lesões nos direcionam para uma possível ligação do chá com toxicidade e morte celular, já que a EGCG também estimula o processo de apoptose ${ }^{(8)}$.

O anticorpo utilizado foi o Shc A, específico para as suas três isoformas ao mesmo tempo, e, portanto, não podemos afirmar qual das três isoformas foi a predominante nos nossos resultados.
Concluindo, neste trabalho observamos que os animais tratados com o chá verde apresentaram diminuição do peso corporal e melhora do GTT.

Observou-se também, no fígado, um aumento da fosforilação do IR e a análise imuno-histoquímica sugeriu alterações na expressão de IR e Shc dos animais obesos tratados com relação aos obesos não submetidos a tratamento.

Apesar de não se ter esperado no presente estudo uma relação direta entre chá verde e efeitos adversos no fígado, observou-se lesões que poderiam ser associadas ao tratamento, tais como necrose focal.

\section{Agradecimentos}

Agradecemos à professora Albanita Vianna de Oliveira pela leitura e pela análise das lâminas deste trabalho e ao apoio financeiro da Fundação Carlos Chagas de Amparo à Pesquisa do Estado do Rio de Janeiro (FAPERJ) .

\section{Referências}

1. BIDDINGER, S. B.; KAHN, C. R. From mice to men: insights into the insulin resistance syndromes. Ann Rev Physiol, v. 68, p. 123-58, 2005.

2. BOSE, M. et al. The major green tea polyphenol, -epigallocatechin-3-gallate, inhibits obesity, metabolic syndrome, and fatty liver disease in high-fat-fed mice. J Nutr, v. 138, p. 1677-83, 2008.

3. COSENTINO, F. et al. Final common molecular pathways of aging and cardiovascular disease: role of the p66Shc protein. Arterioscler Thromb Vasc, v. 28, p. 622-8, 2008.

4. HOTCHKISS, R. S. et al. Cell death. N Engl J Med, v. 361, n. 16, p. 1570-83, 2009.
5. MAZZANTI, G. et al. Hepatotoxicity from green tea: a review of the literature and two unpublished cases. Eur J Clin Pharmacol, v. 65, p. 331-41, 2006.

6. MIGLIACCIO, E. et al. Apoptosis and aging: role of p66Shc redox protein. Antioxid Redox Signal, v. 8, n. 4, p. 600-8, 2006.

7. SAAD, M. J. A. et al. Regulation of insulin receptor substrate- 1 in liver and muscle of animal models of insulin resistance. J Clin Invest, v. 90, p.1839-49, 1992.

8. YANG, C. S. et al. Cancer prevention by tea: animal studies, molecular mechanisms and human relevance. Nat Rev Cancer, v. 9, n. 6, p. 429-39, 2009. 